\title{
A proposed new clinical staging system for patients with mucosal leishmaniasis
}

\author{
Hélio A. Lessa ${ }^{a}$, Marcus M. Lessa ${ }^{a}$, Luiz Henrique Guimarães ${ }^{a}$, Clara Mônica F. Lima $^{a}$, \\ Sergio Arruda ${ }^{a}$, Paulo R. Machado ${ }^{a}$, and Edgar M. Carvalho ${ }^{a, b}$ \\ aServiço de Imunologia, Complexo Hospitalar Universitário Professor Edgard Santos, \\ Universidade Federal da Bahia, Salvador, BA, Brazil \\ 'bInstituto Nacional de Ciência e Tecnologia de Doenças Tropicais, Salvador, BA, Brazil
}

\section{Abstract}

Mucosal leishmaniasis occurs mainly in areas where Leishmania braziliensis is transmitted. It affects predominantly the nasal mucosa and, in more severe forms, can lead to significant tissue destruction. There is no standard method for grading the severity of disease. We categorised 50 patients with mucosal leishmaniasis according to a proposed clinical staging system. Their age ranged from 10 to $86 \mathrm{y}$ (mean \pm SD: $36 \pm 16 \mathrm{y}$ ) and $43(86 \%)$ patients were male. The different degrees of evolution of mucosal disease, from the initial stage to the more severe long-term cases, enabled mucosal leishmaniasis to be graded into five stages. Stage I is characterised by nodular lesions of the mucosa without ulcerations. Stage II is represented by superficial mucosal ulcerations with concomitant fine granular lesions. Stage III is characterised by deep mucosal ulcerations with granular tissue formation. In stage IV there are irreversible lesions leading to perforation of the cartilaginous nasal septum with necrosis. In stage $\mathrm{V}$ the nasal pyramid is compromised with alterations of facial features as a consequence of severe tissue destruction. These stages may be useful in characterising the severity of the lesion and optimising the therapeutic outcome.

\section{Keywords}

Leishmaniasis; Mucosal leishmaniasis; Disease stage; Nasal mucosa; Nose diseases; Brazil

\footnotetext{
(C) 2012 Royal Society of Tropical Medicine and Hygiene. Published by Elsevier Ltd. All rights reserved.

Correspondence to: Edgar M. Carvalho.

Present address: Serviço de Imunologia, $5^{\circ}$ andar, Hospital Universitário Professor Edgard Santos, Rua João das Botas, s/n, 40110160, Canela, Salvador, BA, Brazil. Tel.: +55 713237 7353; fax: +55 713245 7110. edgar@ufba.br, imuno@ufba.br

Authors' contributions: HAL, MML and EMC conceived and designed the study; HAL, MML, CMFL and SA analysed the data; HAL, MML, LHG, SA, PRM and EMC interpreted the data; HLA, MML, CMFL and SA drafted the manuscript; HAL, MML, LHG, PRM and EMC critically revised the manuscript for intellectual content. All author read and approved the final manuscript. EMC is guarantor of the paper.

Competing interests: None declared.

Ethical approval: The study was approved by the Ethics Committee of the Professor Edgard Santos University Hospital, Salvador, BA, Brazil.

Publisher's Disclaimer: This is a PDF file of an unedited manuscript that has been accepted for publication. As a service to our customers we are providing this early version of the manuscript. The manuscript will undergo copyediting, typesetting, and review of the resulting proof before it is published in its final citable form. Please note that during the production process errors may be discovered which could affect the content, and all legal disclaimers that apply to the journal pertain.
} 


\section{Introduction}

Leishmaniasis has been documented in many countries, with an estimated worldwide prevalence of 12 million cases and 1-1.5 million new cases of the disease reported annually. American tegumentary leishmaniasis is endemic in Brazil and most of Latin America. ${ }^{1}$

Tegumentary leishmaniasis is more frequent than the visceral form of the disease and is characterised, in its classic form, by the presence of a clearly delineated skin ulcer with raised edges. ${ }^{1-3}$ Nearly $3 \%$ of patients diagnosed with cutaneous leishmaniasis (CL), living in an area of Leishmania braziliensis transmission, will concomitantly or subsequently develop mucosal disease. ${ }^{4}$ The nasal mucosa is the primary location for lesions caused by $L$. braziliensis in mucosal leishmaniasis (ML), and lesions may spread beyond the nasal mucosa to the upper airways and digestive tract of humans (larynx and pharynx). However, the preferential site of disease is the cartilaginous nasal septum and frontal portions of the nasal fossa. ${ }^{5,6}$ Due to variable involvement of the mucosa, patients with ML present with different clinical symptoms and have different therapeutic responses depending on the severity of lesions. ${ }^{7,8}$ For clinical studies and for evaluation of response to treatment, it is necessary to standardise the diverse stages of ML. Based on complete endoscopic otolaryngological examinations we attempted to categorise ML into five stages, ranging from the presence of a mucosal nodular lesion without ulcerations to a stage characterised by the destruction of nasal architecture with gross facial alterations.

\section{Patients and methods}

\subsection{Patient selection}

Fifty patients diagnosed with ML in the health post of Corte de Pedra participated in the study. This is a known area of L. braziliensis transmission, located in southeast Bahia, Brazil. Participants in the study were enrolled between January 1996 and December 1998 and also between January 2005 and December 2008. Eligible patients were those with a typical mucosal lesion of leishmaniasis, a positive skin test for Leishmania antigen, and either isolation of the parasite or histopathological findings characteristic of ML. All patients had signs of active disease. After obtaining signed informed consent, each patient was clinically evaluated. In all cases, clinical background information was collected and physical and otolaryngological examinations were carried out. During the physical examination, special attention was given to the identification of scars compatible with past CL disease. All patients had signs of active disease and were treated with i.v. pentavalent antimony $\left(\mathrm{Sb}^{\mathrm{v}}\right)$ for $30 \mathrm{~d}$ (20 mg/kg/body weight).

\subsection{Otolaryngological examination}

An otolaryngological examination was carried out on all CL patients with nasal complaints, including runny nose, epistaxis or nasal obstruction. It was also performed on all patients who presented with disseminated leishmaniasis or those with facial lesions, as an association has been demonstrated between ML and disseminated forms of CL involving the face. ${ }^{9}$ This examination led to the diagnosis of ML in 50 patients.

The complete endoscopic otolaryngological examination included an inspection of the anterior and posterior nose, as well as the nasopharynx and the oropharynx, using a $3.2 \mathrm{~mm}$ flexible endoscope. For patients suspected of having more widespread lesions, endoscopies of the pharynx and larynx were performed with a $70^{\circ} 8 \mathrm{~mm}$ rigid endoscope. 


\section{Results}

Analysis of the 50 patients revealed five clear stages of ML (Table 1): $2(4 \%)$ were stage I, $18(36 \%)$ were stage II, $6(12 \%)$ were stage III, $22(44 \%)$ were stage IV and $2(4 \%)$ were stage $\mathrm{V}$. The stage of the lesions ranged from nasal nodulation without ulceration to superficial ulceration, deep ulceration and perforation of the septum. In the initial stage the disease is characterised by nodular lesions without ulcerations normally along the cartilaginous septum (Kiesselbach area), nasal floor and lateral wall (specifically on the tip of the inferior nasal conchae) (Figure 1A). Patients with stage I disease can be asymptomatic or have mild symptoms. In this study, patients classified as stage I had mild symptoms like non-bloody rhinorrhea and some nasal obstruction. Asymptomatic patients are often identified only because of systematic otolaryngological examination of patients with disseminated CL and of patients with lesions on the face.

Eighteen (36\%) of the patients had fine granular lesions, characterised by superficial ulcerations observed at the anterior septum, inferior conchae and the floor of the nasal fossa (Figure 1B). In stage II, a few bleeding lesions were observed. Clinically, patients may complain of bloody rhinorrhea and nasal obstruction.

In stage III (deep ulceration stage) the tissue reaction was more intense, with clearly visible tissue granulation and mucosal infiltration, which thickened the nasal septum (Figure 1C). Bloody crusts were observed on the septum, inferior conchae and floor of the nasal fossa. These lesions were characterised by excessive fragility and bled easily when the mucosa was touched. Clinically, patients may complain of a painful sensation in the nasal pyramid. Bloody rhinorrhea, discharge of bloody clots and important nasal obstruction are a common complaint at this stage of disease. In some cases, oedematous infiltration of the nasal pyramid can be observed.

Stage IV is characterised by necrosis of cartilage in the anterior septum and in some cases the nasal columns can be compromised. It is at this stage that the cartilaginous septum is perforated with an accentuated infiltration of the posterior septum (Figure 1D). Clinically, the patient may complain of bloody rhinorrhea, discharge of bloody clots and nasal obstruction.

In its more advanced phases (stage V) total destruction of the nasal columns may occur and the tip of the nose may collapse. The dorsal region of the nasal pyramid is sometimes perforated. In some cases, total destruction of the anterior septum may occur, leaving the entire column exposed and sealing the nose (Figure 2). Extensive crusts with a bloody appearance can be observed due to a widened nasal cavity, represented by the destruction of the cartilaginous septum and inferior conchae. The intensity of the inflammatory process and the subsequent tissue destruction can, therefore, interfere significantly with facial structure. Interestingly, we did not observe myiasis, despite extensive exposure of the internal nasal structures. Clinically, the patient may complain of bloody rhinorrhea, discharge of bloody clots, nasal obstruction and destruction of nasal architecture.

All patients in this study had active lesions. However it is important to point out that stages IV and V can be present in both the active and inactive forms of mucosal disease. In other words, stage IV and stage $\mathrm{V}$ can also be seen in patients with the inactive forms of mucosal disease, as the septal perforation and destruction of nasal architecture are still present even after treatment and resolution of the active lesions.

The characteristic location of the lesion and the stage of the disease in the 50 ML patients studied are presented in Table 2. The age of the patients ranged from 10 to $86 \mathrm{y}$ with a mean and SD of $36 \pm 16 \mathrm{y}$. The majority (94\%) were adults; two patients were $12 \mathrm{y}$ old and one 
patient was $10 \mathrm{y}$ old. Forty-three patients (86\%) were male and 7 (14\%) were female. Of the three children with the disease, two were female. The duration of the mucosal disease ranged from 1 mo to $44 \mathrm{y}$.

A correlation between duration of lesion (symptom) and disease stage was observed, $r=0.6406$ and $\mathrm{p}<0.0001$ (Figure 3). Ninety-two mucosal lesions were documented in the 50 patients: nasal septum, 43; nasal floor, 9; lateral nasal wall, 19; rhinopharynx, 3; oropharynx and palate, 16; and larynx, 2.

A history of cutaneous lesions with evidence of an active cutaneous lesion or the presence of scarring was observed in $46(92 \%)$ patients. Although the majority of cutaneous lesions $(54.2 \%)$ were located in the lower extremities, $44.6 \%$ of the cutaneous lesions were documented on the head, trunk and upper extremities.

Although biopsies were obtained for diagnosis in all patients we were able to recover material and perform a systematic histopathological analysis in only 14 patients. The degree of inflammation was determined by the frequency of lymphocytes, monocytes and plasma cells. Moreover presence and degree of necrosis and epithelium destruction was evaluated. There was no major difference regarding chronic inflammation in stages II, III and IV. However epithelium destruction and necrosis were more evident in patients classified as stage III and IV (Figure 4)

\section{Discussion}

Previous studies have shown that CL and ML predominate in adult males. ${ }^{10,11}$ However, an increasing higher number of cases in children, as well as in both sexes, have been documented. ${ }^{12}$ These findings suggest changes in disease transmission pattern, reinforcing the current importance of peridomiciliary and intradomiciliary transmission. ${ }^{12}$ In our case series, the majority of patients were adult males although it is interesting to note that two of the three children with ML were female.

Previous description of the involvement of the nasal mucosa in leishmaniasis used only anterior rhinoscopy to examine most cases. ${ }^{13,14} \mathrm{Few}$ studies exist in which a complete otolaryngological examination was carried out. ${ }^{15}$ Radiological evaluation of patients with ML has shown erosion of the nasal septum, deformity of the nasal pyramid and alterations of the nasal conchae. ${ }^{16} \mathrm{In}$ a previous study, we called attention to the fact that mucosal involvement, in a high percentage of cases, occurred in the form of multiple lesions, and that this influenced the clinical evolution of the disease and therapeutic response. ${ }^{8}$ In the present study, a staging system for mucosal disease is proposed based on both the appearance and location of lesions. From a clinical viewpoint, the different stages are distinct. However, as there was a relationship between duration of the disease and its stage, different stages may represent different phases of the disease, with the more severe forms being found in patients who have had the disease for longer periods and who have not responded to treatment. The fact that Spearman's correlation was 0.64 and did not reach 1 may indicate that other factors are also involved in disease progression.

The staging of disease has important clinical as well as scientific implications. From a clinical viewpoint, the stage is likely to better characterise the severity of the lesion and may be a more useful way of judging response to therapy. Because patients with stage IV and V disease with active lesions have more severe forms of the disease, they must be treated more aggressively. We have used a combination of antimony with pentoxifylline or amphotericin B for these patients. ${ }^{17,18}$ Although there was no association between the stage of the disease and the number of treatment courses of antimonial used, therapeutic failure and the need to 
use pentoxifylline and amphotericin B occurred predominantly in the patients at stages IV and $\mathrm{V}$ of the disease.

From a scientific viewpoint, the staging system may be important for clinical trials. We suggest that patient randomisation takes into account the stage of the disease so that similar forms of mucosal disease are included in the different study groups.

\section{Conclusion}

Observations of patients with different degrees of evolution of mucosal leishmaniasis, from the initial stage to the more severe end-stage cases, allowed us to categorise the disease into five stages, ranging from the presence of mucosal nodular lesions without ulcerations to an advanced stage characterised by the destruction of nasal architecture and alterations in facial structure.

\section{Acknowledgments}

We acknowledge Elbe Silva for secretarial assistance of in the preparation of the manuscript, Ednaldo Lago for assistance with the patient selection and Michael Sundberg who reviewed the text.

Funding: This study was supported the US National Institutes of Health grant \# AI-30639.

\section{References}

1. Desjeux P. Leishmaniasis: current situation and new perspectives. Comp Immunol Microbiol Infect Dis. 2004; 27:305-18. [PubMed: 15225981]

2. Weigle K, Saravia NG. Natural history, clinical evolution, and the host-parasite interaction in New World cutaneous leishmaniasis. Clin Dermatol. 1996; 14:433-50. [PubMed: 8889321]

3. Carvalho EM, Barral A, Costa JML, Bittencourt AL, Marsden P. Clinical and immunopathological aspects of disseminated cutaneous leishmaniasis. Acta Trop. 1994; 56:315-25. [PubMed: 8023755]

4. Jones TC, Johnson WD, Barreto AC, et al. Epidemiology of American cutaneous leishmaniasis due to Leishmania braziliensis braziliensis. J Infect Dis. 1987; 156:73-83. [PubMed: 3598227]

5. Marsden PD, Llanos-Cuentas EA, Lago EL, et al. Human mucocutaneous leishmaniasis in Três Braços, Bahia-Brazil. An area of Leishmania braziliensis braziliensis transmission. III - Mucosal disease presentation and initial evolution. Rev Soc Bras Med Trop. 1984; 17:179-86.

6. Lessa H, Carvalho EM, Marsden PD. Eustachian tube blockage with consequent middle ear infection in mucosal leishmaniasis. Rev Soc Bras Med Trop. 1994; 27:103. [PubMed: 8073152]

7. Franke ED, Wignall FS, Cruz ME, et al. Efficacy and toxicity of sodium stibogluconate for mucosal leishmaniasis. Ann Intern Med. 1990; 113:934-40. [PubMed: 2173461]

8. Guerreiro JB, Cruz AA, Barral A, Lessa HA, Rocha H, Carvalho EM. Mucosal leishmaniasis: quantitative nasal cytology as a marker of disease activity and indicator of healing. Ann Otol Rhinol Laryngol. 2000; 109:89-94. [PubMed: 10651420]

9. Turetz ML, Machado PR, Ko AI, et al. Disseminated leishmaniasis: a new and emerging form of leishmaniasis observed in northeastern Brazil. J Infect Dis. 2002; 186:1829-34. [PubMed: 12447770]

10. Sampaio RNR, Rocha RAA, Marsden PP, Cuba CC, Barreto AC. American cutaneous leishmaniasis: experience of the UNB hospital. An Bras Dermat. 1980; 55:69-76.

11. Llanos Cuentas EA, Cuba CC, Barreto AC, Marsden PD. Clinical characteristics of human Leishmania braziliensis braziliensis infections. Trans R Soc Trop Med Hyg. 1984; 78:845-6. [PubMed: 6533860]

12. Follador I, Araujo C, Cardoso MA, et al. Outbreak of cutaneous leishmaniasis, Santo Amaro, Bahia (Brazil). Rev Soc Bras Med Trop. 1999; 32:497-503. [PubMed: 10881082]

13. Barbosa JER. Statistical data on cases of mucosal leishmaniasis observed in the ENT service of Santa Casa de San Paulo. Rev Oto-Laringologica de São Paulo. 1936; 4:697-723. 
14. Klotz O, Lindenberg H. The pathology of leishmaniasis of the nose. Am J Trop Med. 1923; 3:11741.

15. Zajtchuk JT, Casler JD, Netto EM, et al. Mucosal leishmaniasis in Brazil. Laryngoscope. 1989; 99:925-39. [PubMed: 2671555]

16. Camargo RA, Tuon FF, Sumi, et al. Mucosal leishmaniasis and abnormalities on computed tomographic scans of paranasal sinuses. Am J Trop Med Hyg. 2010; 83:515-18. [PubMed: 20810813]

17. Machado PR, Lessa H, Lessa M, et al. Oral pentoxifylline combined with pentavalent antimony: a randomized trial for mucosal leishmaniasis. Clin Infect Dis. 2007; 44:788-93. [PubMed: 17304449]

18. Lessa HA, Machado P, Lima F, et al. Successful treatment of refractory mucosal leishmaniasis with pentoxifylline plus antimony. Am J Trop Med Hyg. 2001; 65:87-9. [PubMed: 11508396] 


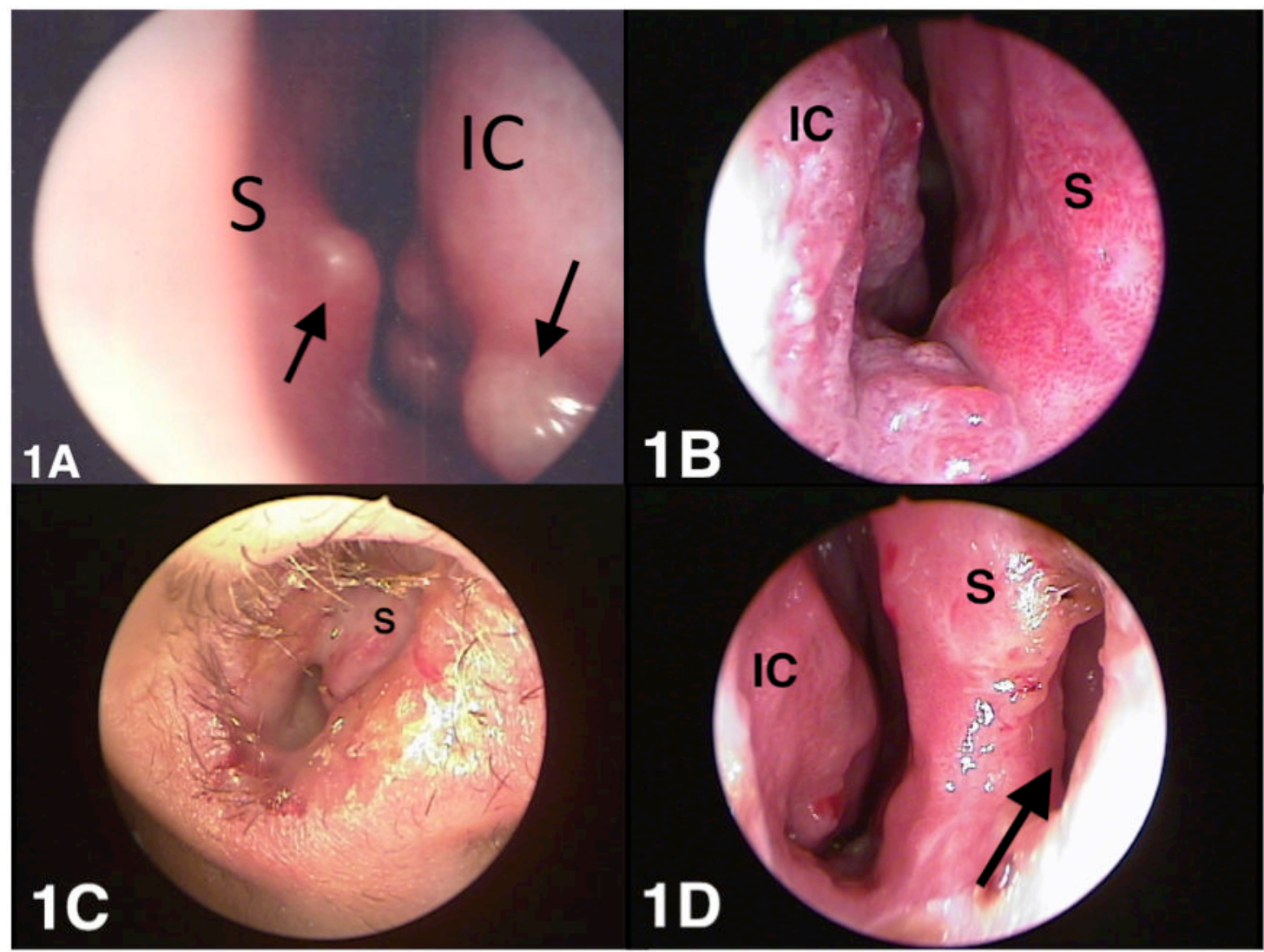

Figure 1.

Clinical aspects of mucosal leishmaniasis at different stages of the disease. (A) Nodular lesions (arrows) without ulcerations along the tip of the inferior nasal conchae and nasal septum (stage I). (B) Fine granular lesions, characterised by superficial ulcerations observed at the inferior conchae and the floor of the nasal fossa (stage II). (C) Deep ulceration stage with more intense tissue reaction and clearly visible tissue granulation and mucosa infiltration (stage III). (D) Cartilaginous nasal septum is perforated (arrow) with a visible tissue granulation and mucosa infiltration of the posterior nasal septum and inferior conchae (stage IV active form). IC: inferior conchae; S: septum. 


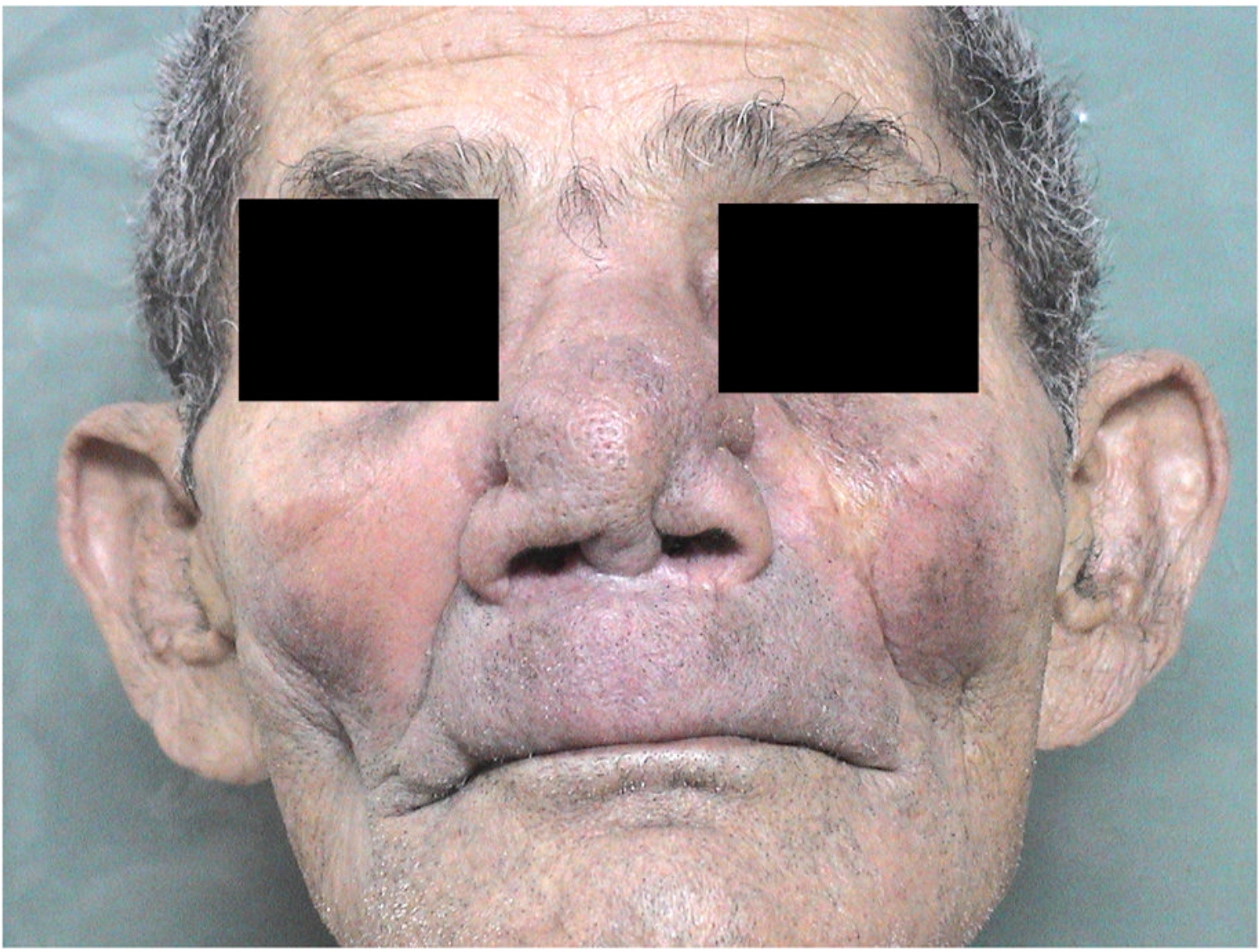

Figure 2.

Total destruction of the anterior septum sealing the nose (stage V). The patient gave informed consent for images taken during the study to be published. 


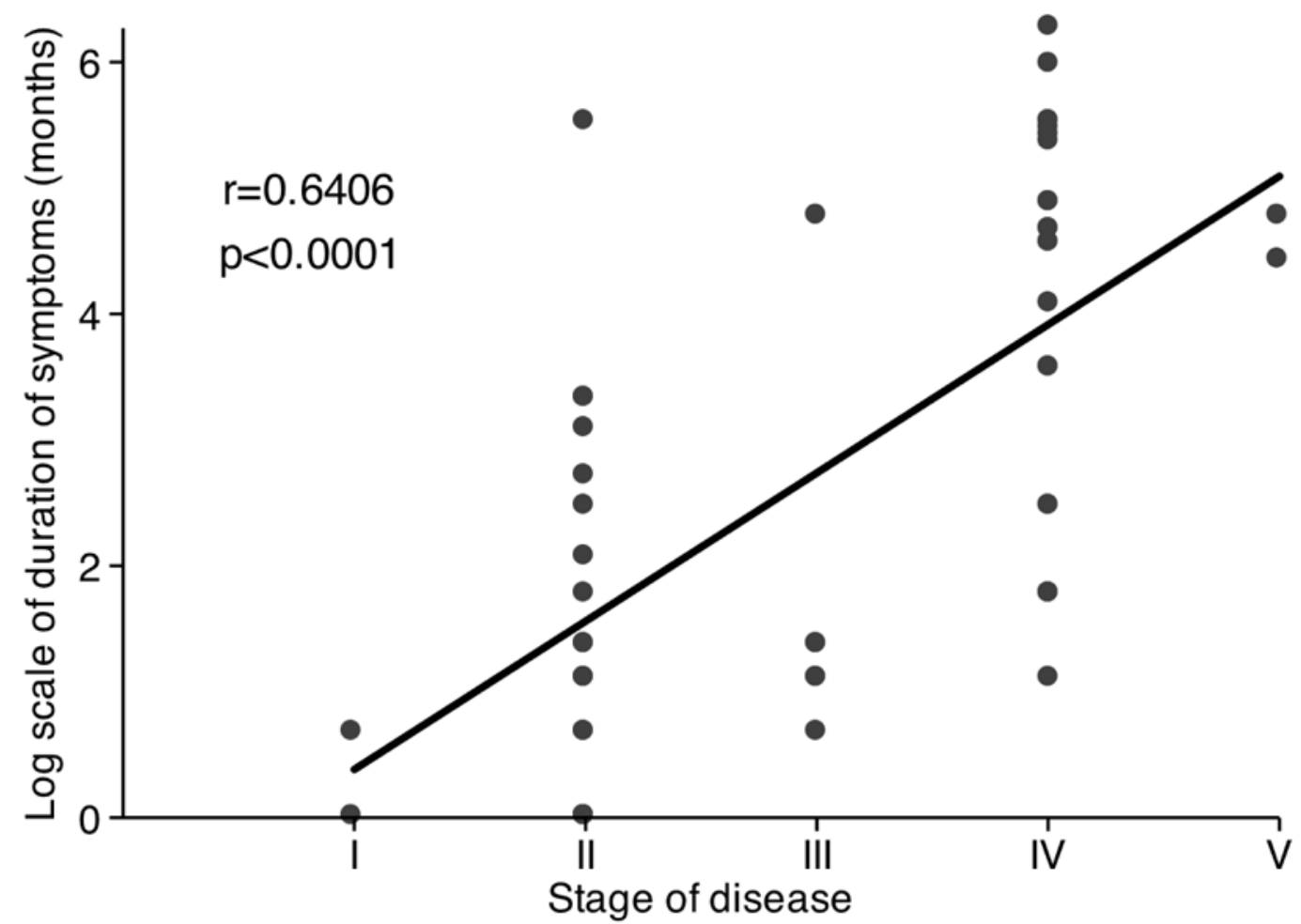

Figure 3.

Correlation between time of symptom (log scale) and stage of disease, (some points overlap). 

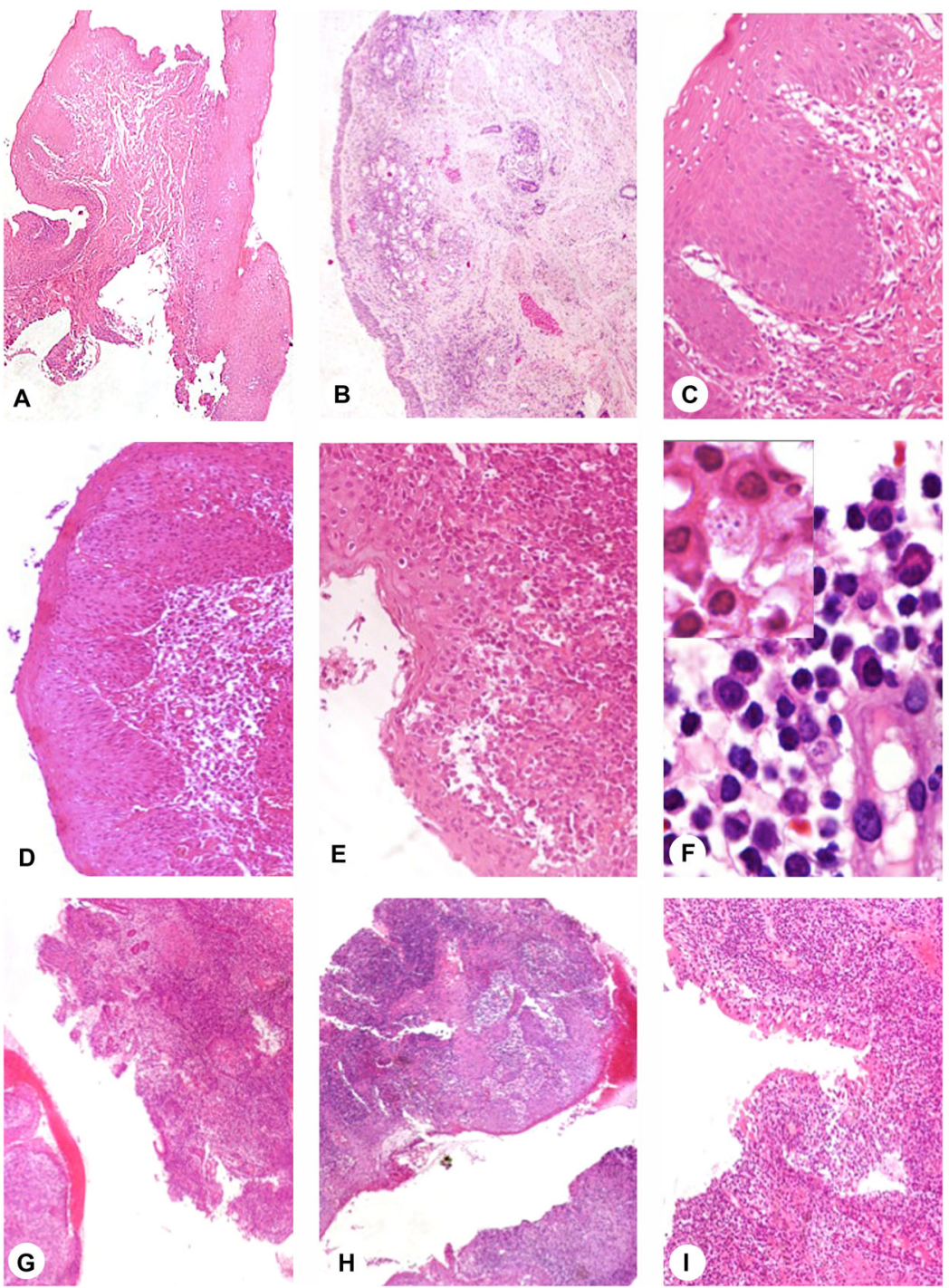

Figure 4.

Histopathological analysis of biopsies from patients with mucosal leishmaniasis (ML). (A) $4 \times$, (B) $4 \times$ and (C) $20 \times$ biopsy from patient with nasal mucosal lesion stage I. (D) $10 \times$ and (E) $20 \times$ biopsy from patient stage II. (F) $100 \times$ detail of inflammatory infiltrate composed of lymphocytes, plasma cells, vessel and macrophages containing Leishmania amastigotes (arrows). (G) $4 \times$, (H) $4 \times$ and (I) $10 \times$ patient with ML stage IV. ML clinical stage I and II are less inflamed without epithelium destruction. In stage IV the inflammation is higher with focus of necrosis and epithelium disruption. 


\section{Table 1}

A proposed new clinical staging system for patients with mucosal leishmaniasis

\begin{tabular}{ll}
\hline Stage & Clinical observations in nasal mucosal disease \\
\hline I & Nodulation without ulcerations \\
II & Superficial ulcerations \\
III & Deep ulcerations \\
IV & Septum perforation \\
V & Destruction of nasal architecture and altered facial structure \\
\hline
\end{tabular}


Table 2

Characteristics of mucosal disease in 50 patients diagnosed with mucosal leishmaniasis

\begin{tabular}{|c|c|c|c|c|}
\hline Age (y) & Gender & Duration of mucosal disease & Location of mucosal lesions & Stage \\
\hline 18 & M & $1 \mathrm{mo}$ & Nasal septum & I \\
\hline 31 & $\mathrm{~F}$ & $2 \mathrm{mo}$ & Nasal septum and oropharynx & I \\
\hline 47 & M & $1 \mathrm{mo}$ & Nasal vestibule and nasal lateral wall & II \\
\hline 15 & M & $1 \mathrm{mo}$ & Nasal septum & II \\
\hline 12 & $\mathrm{~F}$ & $1 \mathrm{mo}$ & Nasal septum & II \\
\hline 34 & M & $1 \mathrm{mo}$ & Nasal floor and septum & II \\
\hline 28 & M & $2 \mathrm{mo}$ & Nasal vestibule and nasal lateral wall & II \\
\hline 55 & M & $2 \mathrm{mo}$ & Nasal septum and soft palate & II \\
\hline 46 & M & $3 \mathrm{mo}$ & Nasal septum & II \\
\hline 38 & M & $3 \mathrm{mo}$ & Nasal septum & II \\
\hline 60 & M & $4 \mathrm{mo}$ & Nasal vestibule, nasal lateral wall and septum & II \\
\hline 43 & M & $4 \mathrm{mo}$ & Nasal septum and inferior conchae & II \\
\hline 21 & M & $6 \mathrm{mo}$ & Nasal septum & II \\
\hline 44 & M & $8 \mathrm{mo}$ & Nasal septum and inferior conchae & II \\
\hline $45^{a}$ & M & $12 \mathrm{mo}$ & Inferior conchae & II \\
\hline 23 & $\mathrm{~F}$ & $15 \mathrm{mo}$ & Nasal septum & II \\
\hline 16 & M & $22 \mathrm{mo}$ & Nasal septum and inferior conchae & II \\
\hline 30 & M & $28 \mathrm{mo}$ & Nasal septum and inferior conchae & II \\
\hline 26 & M & $28 \mathrm{mo}$ & Inferior conchae & II \\
\hline $58^{b}$ & M & $21 \mathrm{y}$ & Floor of the nasal fossa & II \\
\hline 20 & M & $2 \mathrm{mo}$ & Nasal septum and inferior conchae & III \\
\hline 32 & M & $3 \mathrm{mo}$ & Nasal septum, inferior conchae and soft palate & III \\
\hline 23 & M & $3 \mathrm{mo}$ & Nasal floor, septum and nasal lateral wall & III \\
\hline 32 & M & $4 \mathrm{mo}$ & Nasal septum and inferior conchae & III \\
\hline 31 & M & $4 \mathrm{mo}$ & Nasal septum and soft palate & III \\
\hline 69 & M & $10 \mathrm{y}$ & Inferior conchae and oropharynx & III \\
\hline 43 & M & $3 \mathrm{mo}$ & Nasal septum & IV \\
\hline 29 & M & $6 \mathrm{mo}$ & Nasal septum, soft palate and larynx & IV \\
\hline 19 & M & $6 \mathrm{mo}$ & Nasal floor and septum & IV \\
\hline 12 & M & $6 \mathrm{mo}$ & Nasal septum and oropharynx & IV \\
\hline 10 & $\mathrm{~F}$ & $12 \mathrm{mo}$ & Nasal floor and septum & IV \\
\hline 29 & M & $12 \mathrm{mo}$ & Nasal septum and inferior conchae & IV \\
\hline 38 & M & 3 y & Nasal septum and inferior conchae & IV \\
\hline 44 & $\mathrm{~F}$ & $3 y$ & Nasal floor and septum & IV \\
\hline 31 & M & $5 \mathrm{y}$ & Nasal septum & IV \\
\hline 14 & M & 8 y & Nasal septum and soft palate & IV \\
\hline 33 & $\mathrm{~F}$ & $8 \mathrm{y}$ & Nasal floor, septum and inferior conchae & IV \\
\hline 33 & M & $9 y$ & Nasal septum & IV \\
\hline 47 & M & $9 \mathrm{y}$ & Nasal septum & IV \\
\hline
\end{tabular}

Trans R Soc Trop Med Hyg. Author manuscript; available in PMC 2013 June 01. 


\begin{tabular}{|c|c|c|c|c|}
\hline Age (y) & Gender & Duration of mucosal disease & Location of mucosal lesions & Stage \\
\hline 86 & M & 11 y & Nasal septum and soft palate & IV \\
\hline 36 & M & $11 \mathrm{y}$ & Nasal septum & IV \\
\hline 33 & M & $18 \mathrm{y}$ & Nasal septum, soft palate & IV \\
\hline 35 & M & $19 \mathrm{y}$ & Nasal septum & IV \\
\hline 59 & M & $20 \mathrm{y}$ & Nasal septum, rhinopharynx and soft palate & IV \\
\hline 41 & M & 21 y & Nasal septum and nasal lateral wall & IV \\
\hline 30 & M & $21 \mathrm{y}$ & Nasal septum, inferior conchae, rhinopharynx, larynx, soft and hard palate & IV \\
\hline 40 & M & 33 y & Nasal floor, Nasal septum, rhinopharynx and soft palate & IV \\
\hline 60 & $\mathrm{~F}$ & 44 y & Nasal septum, soft palate & IV \\
\hline 64 & M & $10 \mathrm{y}$ & Nasal septum, soft palate & $\mathrm{V}$ \\
\hline 39 & M & $7 \mathrm{y}$ & Nasal septum and soft palate & $\mathrm{V}$ \\
\hline
\end{tabular}

M: male; F: female.

a Patient with disseminated cutaneous leishmaniasis.

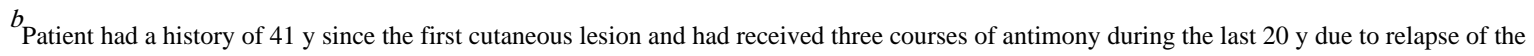
mucosal disease. 